\title{
Isolation and characterization of camelid single-domain antibodies against HER2
}

\author{
Greg Hussack, Shalini Raphael, Michael J. Lowden and Kevin A. Henry*
}

\begin{abstract}
Objective: To isolate and characterize novel high-affinity llama single-domain antibodies against human HER2.

Results: We immunized a llama with human $H E R 2$, constructed a phage-displayed $\mathrm{V}_{\mathrm{H}} \mathrm{H}$ library from the lymphocytes of the animal, and isolated six unique HER2-specific $V_{H} H s$ by panning. All six $V_{H} H s$ were unique at the amino acid level and were clonally unrelated, as reflected by their distinct CDR3 lengths. All six $V_{H} H s$ recognized recombinant human HER2 ectodomain with monovalent affinities ranging from 1 to $51 \mathrm{nM}$, had comparable affinities for cynomolgus monkey HER2, and bound HER2+ SKOV3 cells by flow cytometry. Three of the $V_{H} H s$ recognized recombinant murine HER2 with no loss of affinity compared with human and cynomolgus monkey HER2. The $\mathrm{V}_{H} \mathrm{H}$ s recognized three major epitopes on HER2 (including one conserved across the human, simian and murine orthologues), all of which were distinct from that of trastuzumab. These $\mathrm{V}_{\mathrm{H}} \mathrm{Hs}$ may be useful in the design of modular cancer immunotherapeutics.
\end{abstract}

Keywords: Single-domain antibody, $\mathrm{V}_{\mathrm{H}} \mathrm{H}, \mathrm{HER} 2$, Cancer

\section{Introduction}

HER2/neu (ERBB2, CD340) is a receptor tyrosine kinase of the epidermal growth factor receptor family that is frequently amplified and/or overexpressed in solid tumors [1]. Antibodies (Abs) and Ab-drug conjugates (ADCs) against HER2, exemplified by trastuzumab (Herceptin), pertuzumab (Perjeta) and trastuzumab emtansine (Kadcyla), play an important role in the diagnosis and treatment of breast cancer [2]. Multiple other anti-HER2 $\mathrm{Abs}$ and $\mathrm{Ab}$ fragments are in development as naked antibodies, ADCs, bispecific Abs and radioimmunotherapeutics for breast cancer and other indications [3]. A camelid single-domain $\mathrm{Ab}\left(\mathrm{sdAb}\right.$ or $\left.\mathrm{V}_{\mathrm{H}} \mathrm{H}\right)$ against HER2 is currently in clinical trials for breast cancer imaging [4].

Here, we report the generation and preliminary characterization of a panel of novel llama $\mathrm{V}_{\mathrm{H}} \mathrm{Hs}$ directed against human HER2. Several of the $\mathrm{V}_{\mathrm{H}} \mathrm{Hs}$ have attractive properties that may make them useful components of modular cancer immunotherapeutics.

*Correspondence: kevin.henry@nrc-cnrc.gc.ca

Human Health Therapeutics Research Centre, National Research Council

Canada, 100 Sussex Drive, Ottawa, ON K1A 0R6, Canada

\section{Main text}

We immunized a male llama (Lama glama) with recombinant human HER2 ectodomain (Cat. No. HE2H5225; ACROBiosystems, Beijing, China) as previously described [5-7]. Briefly, the animal was immunized subcutaneously five times with $200 \mu \mathrm{g}$ of human HER2 (days $0,21,28,35$ and 42). The priming immunization was adjuvanted with complete Freund's adjuvant and boost immunizations were adjuvanted with incomplete Freund's adjuvant. Blood samples were collected on days 35 and 49 , from which serum was obtained after clotting and peripheral blood mononuclear cells were purified by density gradient centrifugation. Interestingly, serum ELISA and western blotting indicated that although HER2 immunization elicited polyclonal Abs against the immunizing antigen, immune sera from unrelated animals showed similar degrees of HER2 reactivity (see Additional file 1). We speculate that serum polyreactivity against this recombinant HER2 ectodomain reflects some degree of unfolding and/or aggregation, although binding by trastuzumab and other antibodies indicated that some proportion was also folded correctly.

We constructed a phage-displayed $\mathrm{V}_{\mathrm{H}} \mathrm{H}$ library from the peripheral blood lymphocytes of the HER2-immunized llama as previously described [5-7]. Briefly, total 
Table 1 Properties of HER2-specific $\mathrm{V}_{\mathrm{H}} \mathrm{Hs}$ isolated in this study

\begin{tabular}{|c|c|c|c|c|c|c|c|c|c|c|}
\hline \multirow[t]{2}{*}{$\mathrm{V}_{\mathrm{H}} \mathrm{H}$} & \multirow{2}{*}{$\begin{array}{l}\text { CDR3 } \\
\text { Length } \\
\text { (aa) })^{\mathrm{a}}\end{array}$} & \multicolumn{3}{|c|}{ Human HER2 } & \multicolumn{3}{|c|}{ Cynomolgus HER2 } & \multicolumn{3}{|c|}{ Mouse HER2 } \\
\hline & & $\begin{array}{l}k_{o n} \\
\left(M^{-1} s^{-1}\right)\end{array}$ & $\begin{array}{l}k_{\text {off }} \\
\left(s^{-1}\right)\end{array}$ & $\begin{array}{l}K_{D} \\
(\mathrm{nM})\end{array}$ & $\begin{array}{l}k_{o n} \\
\left(M^{-1} s^{-1}\right)\end{array}$ & $\begin{array}{l}k_{\text {off }} \\
\left(s^{-1}\right)\end{array}$ & $\begin{array}{l}K_{D} \\
(\mathrm{nM})\end{array}$ & $\begin{array}{l}k_{o n} \\
\left(M^{-1} s^{-1}\right)\end{array}$ & $\begin{array}{l}k_{\text {off }} \\
\left(s^{-1}\right)\end{array}$ & $\begin{array}{l}K_{D} \\
(\mathrm{nM})\end{array}$ \\
\hline NRC-sdAb034 & 12 & $5.4 \times 10^{5}$ & $3.4 \times 10^{-3}$ & 6.2 & $5.8 \times 10^{5}$ & $2.7 \times 10^{-3}$ & 4.6 & $5.0 \times 10^{5}$ & $2.9 \times 10^{-3}$ & 5.8 \\
\hline NRC-sdAb035 & 15 & $8.5 \times 10^{5}$ & $4.4 \times 10^{-2}$ & 51 & $1.0 \times 10^{6}$ & $4.3 \times 10^{-2}$ & 41 & & & n.b. \\
\hline NRC-sdAb036 & 19 & $3.9 \times 10^{5}$ & $5.6 \times 10^{-3}$ & 14 & $4.8 \times 10^{5}$ & $5.4 \times 10^{-3}$ & 11 & $4.4 \times 10^{5}$ & $5.8 \times 10^{-3}$ & 13 \\
\hline NRC-sdAb037 & 16 & $4.3 \times 10^{5}$ & $1.7 \times 10^{-2}$ & 39 & $5.1 \times 10^{5}$ & $5.6 \times 10^{-2}$ & 110 & & & n.b. \\
\hline NRC-sdAb038 & 10 & $1.1 \times 10^{6}$ & $1.6 \times 10^{-3}$ & 1.4 & $1.0 \times 10^{6}$ & $1.4 \times 10^{-3}$ & 1.3 & $1.1 \times 10^{6}$ & $1.0 \times 10^{-3}$ & 0.9 \\
\hline NRC-sdAb039 & 18 & $1.4 \times 10^{6}$ & $4.5 \times 10^{-3}$ & 3.3 & $1.7 \times 10^{6}$ & $6.0 \times 10^{-3}$ & 3.6 & & & n.b. \\
\hline
\end{tabular}

n.b. no binding

a IMGT numbering

RNA was extracted in 16 replicates from peripheral blood mononuclear cells (eight samples each from the day 35 and 49 bleeds, each containing $\sim 1 \times 10^{7}$ cells) using the PureLink ${ }^{\mathrm{TM}}$ RNA Mini Kit (Thermo Fisher, Waltham, MA). Approximately 1-2 $\mu \mathrm{g}$ of total RNA was reverse transcribed using qScript ${ }^{\circledR}$ cDNA SuperMix (Quantabio, Beverly, MA) and then rearranged $\mathrm{V}_{\mathrm{H}} \mathrm{H}$ exons were amplified using semi-nested PCR and cloned into the pMED1 phagemid vector. The final library size was $\sim 8 \times 10^{7}$ independent transformants with an insert rate of $\sim 92 \% . \mathrm{V}_{\mathrm{H}} \mathrm{H}$-displaying phages were rescued from library phagemid-bearing Escherichia coli TG1 cells using M13KO7 helper phage (New England Biolabs, Ipswich, MA), panned for four rounds against human HER2 directly immobilized in wells of microtiter plates, and eluted with triethylamine as previously described [5-7]. At the conclusion of four rounds of panning, 96 individual clones (48 each from rounds 3 and 4) were tested for binding to human HER2 by ELISA, yielding six unique and clonally unrelated $\mathrm{V}_{\mathrm{H}} \mathrm{H}$ sequences (Table 1 ).

The DNA sequences encoding the six $\mathrm{V}_{\mathrm{H}} \mathrm{Hs}$ were cloned into the pSJF2H expression vector [8]. C-terminally c-Myc- and $\mathrm{His}_{6}$-tagged $\mathrm{V}_{\mathrm{H}} \mathrm{Hs}$ were expressed in $200 \mathrm{~mL}$ overnight cultures of E. coli TG1 under IPTG induction and purified by $\mathrm{Ni}^{2+}$ affinity chromatography as previously described [5-7]. All six $\mathrm{V}_{\mathrm{H}} \mathrm{Hs}$ were primarily monomeric by size exclusion chromatography, although trace aggregates or impurities were observed for NRC-sdAb035 and NRC-sdAb037 (Fig. 1a). We immobilized human (ACROBiosystems HE2-H5225), cynomolgus (ACROBiosystems $\mathrm{HE} 2-\mathrm{C} 52 \mathrm{Hb}$ ) and murine HER2 (ACROBiosystems ER2-M5220) ectodomains on adjacent flow cells of a CM5 Series S sensor

\footnotetext{
(See figure on next page.)

Fig. 1 Characterization of anti-HER2 llama $V_{H} H$ s. a Size exclusion chromatography profiles of anti-HER2 $V_{H} H s$. Approximately $0.5 \mathrm{mg}$ of each $V_{H} H$ was injected over a Superdex ${ }^{\mathrm{TM}} 75 \mathrm{GL}$ column (GE Healthcare) connected to an ÄKTA FPLC protein purification system (GE Healthcare) in a mobile phase consisting of HBS-EP + (10 mM HEPES, pH 7.4, containing $150 \mathrm{mM} \mathrm{NaCl}, 3 \mathrm{mM}$ EDTA and 0.05\% surfactant P20). Maximum $\mathrm{A}_{280}$ values were normalized to 100 for each $V_{H} H$. b Single-cycle kinetic analysis of $V_{H} H$ s binding to human HER2 by SPR. All $V_{H} H$ s were purified by preparative size exclusion chromatography prior to analysis. Approximately 1323 response units (RUs) of human HER2 were immobilized on adjacent flow cells of a CM5 Series S sensor chip in $10 \mathrm{mM}$ acetate, $\mathrm{pH}$ 4.0, using an amine coupling kit (GE Healthcare). An ethanolamine-blocked flow cell served as the reference. Monomeric $V_{H} H$ s at concentrations ranging from 1-400 nM were injected over the surfaces in HBS-EP+ buffer at a flow rate of $40 \mu \mathrm{L} \mathrm{min}^{-1}$. The contact time was $120 \mathrm{~s}$ and the dissociation time was $600 \mathrm{~s}$. The surfaces were regenerated using $10 \mathrm{mM}$ glycine, $\mathrm{pH}$ 1.5. Data were analyzed using Biacore T200 Software v3.0 (GE Healthcare) and fitted to a 1:1 binding model (black lines show data and red lines show fits). Affinity and kinetic parameters $\left(25^{\circ} \mathrm{C}\right)$ are shown in Table 1, and sensorgrams showing binding to cynomolgus and murine HER2 are shown in Additional file 2. c Binding of $\mathrm{V}_{\mathrm{H}} \mathrm{Hs}$ to HER2 ${ }^{+}$SKOV3 cells by flow cytometry. SKOV3 cells were grown to $70-80 \%$ confluency at $37^{\circ} \mathrm{C}$ in a humidified $5 \% \mathrm{CO}_{2}$ atmosphere in RPMI-1640 medium supplemented with $10 \%$ fetal bovine serum, $100 \mathrm{U} \mathrm{mL}^{-1}$ penicillin, $100 \mu \mathrm{gL}^{-1}$ streptomycin and $250 \mathrm{ng} \mathrm{mL}^{-1}$ amphotericin B. Cells were dissociated from flasks using Accutase ${ }^{\circledR}$ solution, washed in PBS and then resuspended in PBS containing

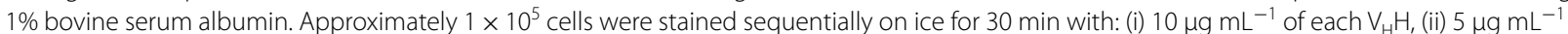
of mouse anti-c-Myc lgG (clone 9E10), and (iii) $5 \mu \mathrm{g} \mathrm{mL}^{-1}$ of APC-conjugated goat anti-mouse lgG (Thermo-Fisher). The cells were washed with PBS in between each staining step, and after the final wash, data (10,000 events) were acquired on a BD FACSCanto ${ }^{\mathrm{TM}}$ instrument (BD Biosciences, San Jose, CA). $\mathbf{d}$ Summary of epitope binning of anti-HER2 $V_{H} H$ s by SPR. HER2 was immobilized as described in B. In the first injection, each $V_{H} H$ at a concentration equivalent to $20 \times K_{D}$ or trastuzumab $(20 \mathrm{nM})$ was injected at a flow rate of $20 \mu \mathrm{L} \mathrm{s}^{-1}$ for $300 \mathrm{~s}$ contact time to saturate the HER2 surface. The second injection consisted of the same $\mathrm{V}_{\mathrm{H}} \mathrm{H}$ along with a second $\mathrm{V}_{\mathrm{H}} \mathrm{H}$ (both at $20 \times$ their respective $K_{D} s$ ). All co injection experiments were performed in both orientations. Blue circles represent distinct epitopes conserved between human and cynomolgus HER2, and green circle represents a distinct epitope conserved across human, cynomolgus and mouse HER2
} 


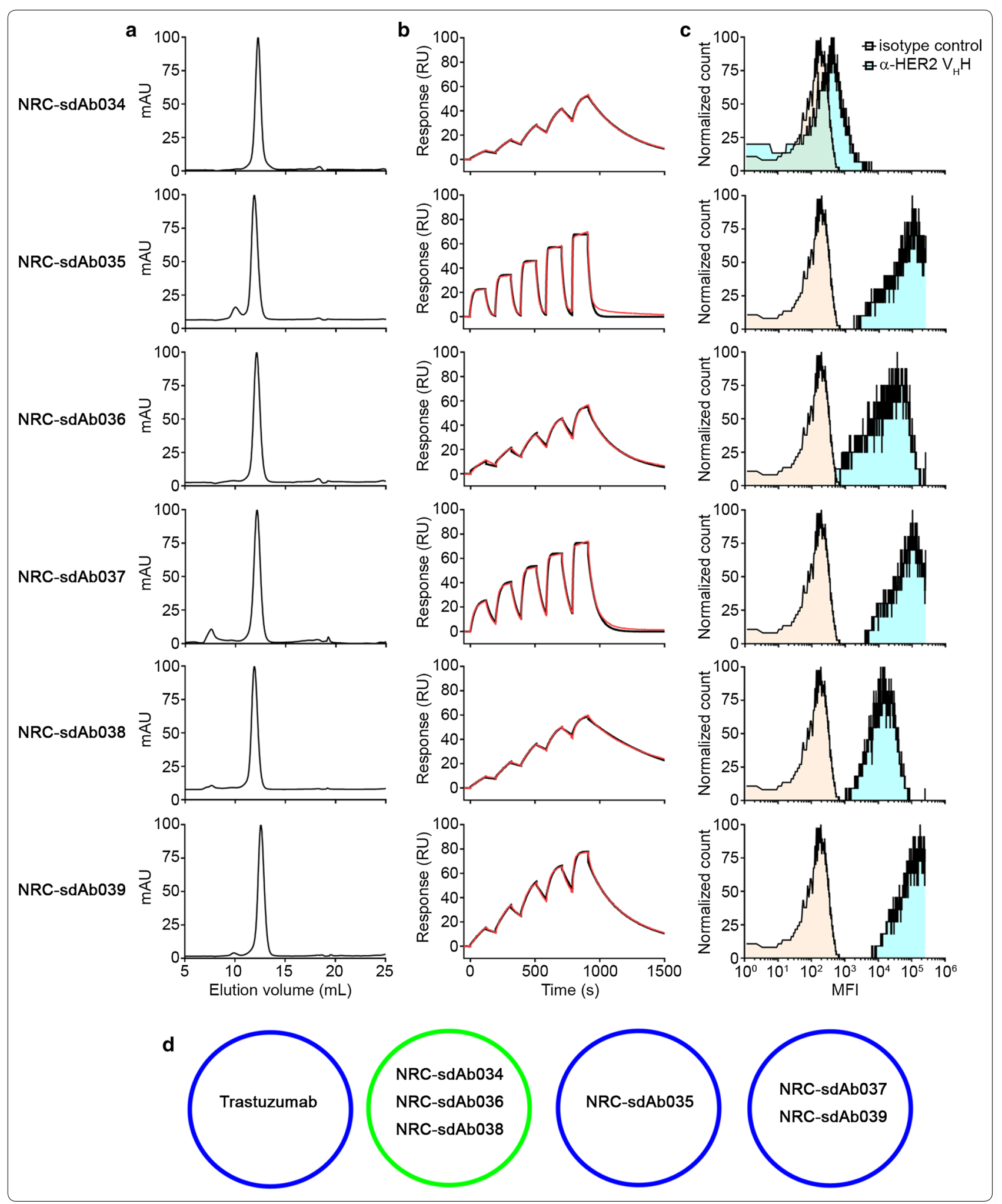


chip (GE Healthcare, Piscataway, NJ) by amine coupling and analyzed binding of the $\mathrm{V}_{\mathrm{H}} \mathrm{Hs}$ to each surface using single-cycle kinetics on a Biacore T200 surface plasmon resonance (SPR) instrument (GE Healthcare). All six $\mathrm{V}_{\mathrm{H}} \mathrm{Hs}$ showed high-affinity binding to HER2 $\left(K_{D}\right.$ range 1-51 nM), with nearly equivalent kinetic and affinity parameters observed for human and cynomolgus HER2 (Fig. 1b, Table 1 and Additional file 2); moreover, three of the $\mathrm{V}_{\mathrm{H}} \mathrm{Hs}$ also cross-reacted with murine HER2 with no apparent loss of binding affinity. All six $\mathrm{V}_{\mathrm{H}} \mathrm{Hs}$ bound to HER2 $^{+}$SKOV3 cells by flow cytometry, although staining by NRC-sdAb034 was weak (Fig. 1c). Epitope binning experiments indicated that despite their unique amino acid sequences, all three cross-reactive $\mathrm{V}_{\mathrm{H}} \mathrm{Hs}$ (NRCsdAb034, NRC-sdAb036 and NRC-sdAb038) targeted a nearly identical epitope (Fig. $1 \mathrm{~d}$ and Additional file 3); the epitopes of NRC-sdAb037 and NRC-sdAb039 also showed a high degree of overlap, while NRC-sdAb035's epitope was distinct. The epitopes of all six $\mathrm{V}_{\mathrm{H}} \mathrm{Hs}$ were distinct from the trastuzumab epitope.

In summary, we have reported the isolation and preliminary characterization of six novel anti-HER2 llama $\mathrm{V}_{\mathrm{H}} \mathrm{Hs}$. Interestingly, despite their unique and clonally unrelated sequences, the $\mathrm{V}_{\mathrm{H}} \mathrm{Hs}$ targeted only three major epitopes on HER2, including an apparently immunodominant epitope conserved across the human, simian and murine orthologues. The nearly identical binding of the $\mathrm{V}_{\mathrm{H}} \mathrm{Hs}$ to cynomolgus HER2 would permit toxicity assessment and, for mouse crossreactive $\mathrm{V}_{\mathrm{H}} \mathrm{Hs}$, evaluation in syngeneic tumor models in combination with immunomodulatory agents. Several other groups have described anti-HER2 $\mathrm{V}_{\mathrm{H}} \mathrm{Hs}$ and characterized them in some detail [9], but in most cases cross-reactivity with murine HER2 was not assessed. Moreover, targeting of a non-trastuzumab epitope is clearly an advantage for imaging of patients being dosed with Herceptin/Kadcyla [10]. The other major potential advantage of these $\mathrm{V}_{\mathrm{H}} \mathrm{Hs}$ in comparison with conventional antibodies is their modularity, which would permit facile incorporation into multifunctional biologics.

\section{Limitations}

At the current time, we have not been able to explore whether these $\mathrm{V}_{\mathrm{H}} \mathrm{Hs}$ have anti-cancer activity. We do not know: (i) the precise locations of their epitopes on HER2, (ii) whether any of the $\mathrm{V}_{\mathrm{H}} \mathrm{Hs}$ inhibit HER2 signaling or inhibit receptor dimerization, permitting their development as naked $\mathrm{Ab}$ therapeutics, (iii) whether any of the $\mathrm{V}_{\mathrm{H}} \mathrm{Hs}$ internalize into HER2 ${ }^{+}$tumor cells, permitting their development as ADCs or radioimmunotherapeutics, or (iv) whether their sequences can be humanized without loss of stability or binding affinity. Moreover, we are unable to disclose the amino acid sequences of these $\mathrm{V}_{\mathrm{H}} \mathrm{Hs}$ for intellectual property reasons. In future studies, we hope to comprehensively investigate the roles of molecular size, valency and serum half-life on tumor uptake using anti-HER2 $\mathrm{V}_{\mathrm{H}} \mathrm{H}$-based biologics as a model system.

\section{Additional files}

Additional file 1: Figure S1. Polyclonal antibody responses after immunization with human HER2 ectodomain.

Additional file 2: Figure S2. Complete sensorgrams for single-cycle kinetic analysis of $\mathrm{V}_{\mathrm{H}} \mathrm{Hs}$ binding to HER2 by SPR.

Additional file 3: Figure S3. Complete sensorgrams for epitope binning SPR co-injection experiments.

\section{Abbreviations \\ Ab: antibody; ADC: antibody-drug conjugate; $s d \mathrm{Ab}$ or $\mathrm{V}_{\mathrm{H}} \mathrm{H}$ : single-domain antibody; SPR: surface plasmon resonance.}

\section{Authors' contributions}

$\mathrm{KAH}$ designed the study, $\mathrm{KAH}$ and MJL isolated the $\mathrm{V}_{H} \mathrm{Hs}$, SR and GH performed and analyzed SPR experiments. All authors read and approved the final manuscript.

\section{Acknowledgements}

We gratefully acknowledge Qingling Yang for technical assistance.

\section{Competing interests}

The authors declare that have no competing interests.

Availability of data and materials

All data generated or analyzed during this study are included in this published article and its additional files.

\section{Consent for publication \\ Not applicable.}

\section{Ethics approval and consent to participate}

Experiments involving animals were conducted using protocols approved by the National Research Council Canada Animal Care Committee and in accordance with the guidelines set out in the OMAFRA Animals for Research Act, R.S.O. 1990, c. A.22.

Funding

This work was funded by the National Research Council Canada.

\section{Publisher's Note}

Springer Nature remains neutral with regard to jurisdictional claims in published maps and institutional affiliations.

Received: 29 August 2018 Accepted: 26 November 2018 Published online: 05 December 2018 


\section{References}

1. Yan M, Schwaederle M, Arguello D, Millis SZ, Gatalica Z, Kurzrock R. HER2 expression status in diverse cancers: review of results from 37,992 patients. Cancer Metastasis Rev. 2015;34:157-64.

2. Loibl S, Gianni L. HER2-positive breast cancer. Lancet. 2017;389:2415-29.

3. Yu S, Liu Q, Han X, Qin S, Zhao W, Li A, et al. Development and clinical application of anti-HER2 monoclonal and bispecific antibodies for cancer treatment. Exp Hematol Oncol. 2017;6:31.

4. Keyaerts M, Xavier C, Heemskerk J, Devoogdt N, Everaert H, Ackaert C, et al. Phase I study of ${ }^{68 G a}$ HER2-nanobody for PET/CT assessment of HER2 expression in breast carcinoma. J Nucl Med. 2016:57:27-33.

5. Baral TN, MacKenzie R, Arbabi Ghahroudi M. Single-domain antibodies and their utility. Curr Protoc Immunol. 2013;103:2-17.

6. Henry KA, Hussack G, Collins C, Zwaagstra JC, Tanha J, MacKenzie CR. Isolation of TGF- $\beta$-neutralizing single-domain antibodies of predetermined epitope specificity using next-generation DNA sequencing. Protein Eng Des Sel. 2016;29:439-43.

7. Henry KA, Tanha J, Hussack G. Identification of cross-reactive singledomain antibodies against serum albumin using next-generation DNA sequencing. Protein Eng Des Sel. 2015;28:379-83.

8. Arbabi-Ghahroudi M, To R, Gaudette N, Hirama T, Ding W, Mackenzie R, et al. Aggregation-resistant $V_{H}$ s selected by in vitro evolution tend to have disulfide-bonded loops and acidic isoelectric points. Protein Eng Des Sel. 2009:22:59-66.

9. Vaneycken I, Devoogdt N, Van Gassen N, Vincke C, Xavier C, Wernery U, et al. Preclinical screening of anti-HER2 nanobodies for molecular imaging of breast cancer. FASEB J. 2011;25:2433-46.

10. Pruszynski M, D'Huyvetter M, Bruchertseifer F, Morgenstern A, Lahoutte T. Evaluation of an anti-HER2 nanobody labeled with ${ }^{225} \mathrm{Ac}$ for targeted a-particle therapy of cancer. Mol Pharm. 2018;15:1457-66.
Ready to submit your research? Choose BMC and benefit from:

- fast, convenient online submission

- thorough peer review by experienced researchers in your field

- rapid publication on acceptance

- support for research data, including large and complex data types

- gold Open Access which fosters wider collaboration and increased citations

- maximum visibility for your research: over $100 \mathrm{M}$ website views per year

At BMC, research is always in progress.

Learn more biomedcentral.com/submissions 